\title{
Santiago de las Atalayas, "sepultura de forasteros". Pleito entre sus vecinos por el traslado de la ciudad, 1780-1799
}

Resumen: Este artículo analiza el traslado de la ciudad de Santiago de las Atalayas, en 1780, a la luz del ideal de ciudad y de las condiciones ambientales y físicas que expresaron quienes estuvieron a favor o en contra de esta determinación, lo cual permite comprender cómo una comunidad entendía la ciudad y procuraba su sostenimiento y perdurabilidad por medio de diferentes estrategias y de los argumentos que expuso cada bando. Un traslado del centro urbano genera interrogantes orientados a conocer qué factores contribuían al sostenimiento o permanencia de los mismos y por qué eran aceptados o rechazados cuando se procuraba su conservación.

Palabras clave: traslado de ciudades, comunidad política, cultura política, historia urbana.

\section{Santiago de las Atalayas, "sepultura de forasteros". Confrontation between neighbors because of the transfer of the city, 1780-1799}

Abstract: This article analyzes the transfer of the city of Santiago de las Atalayas in 1780, analyzing the city ideals of the time and the diverse environmental and physical conditions expressed by those in favor or against this determination. The article explores how a community understood the city and the diverse strategies to procure its sustainability and durability. The transfer of an urban center generates questions about the factors that contributed to the sustainability or permanence of cities and why they were accepted or rejected when their preservation was sought.

Keywords: transfer of cities, political community, political culture, urban history.

\section{Santiago de las Atalayas, "sepultura de forasteiros". Confronto entre vizinhos para a transferência da cidade, 1780-1799}

Resumo: Este artigo analisa a transferência da cidade Santiago de las Atalayas, em 1780, à luz do ideal de cidade e das condições ambientais e físicas que foram expressas por aqueles que eram a favor ou contra esta determinação. Isso nos permite entender como uma comunidade percebia a cidade e buscou sua sustentabilidade e durabilidade por meio de diferentes estratégias e os argumentos apresentados por cada grupo. Uma transferência do centro urbano gera questões que visam saber quais fatores contribuíram para a sustentabilidade ou permanência dos mesmos e por que eram aceitos ou rejeitados quando da busca de sua preservação.

Palavras-chave: transferência da cidade, comunidade política, cultura política, história urbana.

Cómo citar este artículo: Yirla Marisol Acosta Franco, "Santiago de las Atalayas, 'sepultura de forasteros'. Pleito entre sus vecinos por el traslado de la ciudad, 1780-1799”, Trashumante. Revista Americana de Historia Socia/13 [2019]: 108-130. DOI: 10.17533/udea.trahs.n13a05

. Fecha de recepción: 24 de febrero de 2018

Fecha de aprobación: 8 de agosto de 2018

Yirla Marisol Acosta Franco: Magíster en Historia por la Universidad de Antioquia.

Correo electrónico: ymarisol05@gmail.com 


\section{Santiago de las Atalayas, "sepultura de forasteros". Pleito entre sus vecinos por el traslado de la ciudad, 1780-1799`}

Yirla Marisol Acosta Franco

\section{Introducción}

a ciudad en la América hispana desempeñó un papel fundamental en el proceso Lde incorporación de los nuevos territorios y sus recursos bajo el dominio de la monarquía española. La fundación de centros urbanos, su sostenimiento y conservación estuvieron ligados a una serie de directrices emanadas por la Corona y a las circunstancias contextuales de cada región. Los estudios en esta materia han tenido diversos enfoques que parten de la concepción de lo que era la ciudad en el pensamiento político de la época y lo que representaba para los gobiernos y habitantes. Existen dos términos que forman parte de la definición de ciudad: la civitas y la urbs. El primero aludía al cuerpo político que se asentaba en un lugar para vivir bajo un mismo gobierno y, el segundo, a la estructura urbanística: edificios principales, casas, calles y plazas. ${ }^{1}$

Este pensamiento, heredado de la antigüedad, también consideraba a la ciudad como ese espacio en donde era posible desarrollar una vida perfecta en términos del gobierno, de la virtud y de la felicidad, según Aristóteles. ${ }^{2}$ Esta expectativa de perfección encontraba asidero en una ciudad bien trazada, en términos geométricos, en la que se tuviera presente la dirección de los vientos, las defensas, las calles principales y los edificios públicos y religiosos. ${ }^{3}$ Puede pensarse, además, la ciudad como un cuerpo con un diseño orgánico de corte geométrico. ${ }^{4}$ Con esto, vemos una dicotomía entre una ciudad que se definía por sus condiciones físicas y otra

* Este artículo fue producido en el marco de la estrategia de sostenibilidad (2017-2018) del Grupo de Investigación en Historia Social de la Universidad de Antioquia.

1. Sebastián de Covarrubias, Tesoro de la lengua castellana o española (Madrid: Luis Sánchez, 1611).

2. Aristóteles, Política (Madrid: Centro de Estudios Políticos y Constitucionales, 1997).

3. Yirla Marisol Acosta Franco, "Traslados y abandonos de ciudades y villas en el Nuevo Reino de Granada y Popayán, siglos XVI y XVII” (Tesis de maestría en Historia, Universidad de Antioquia, 2017).

4. Richard Sennett, Carne y piedra. El cuerpo y la ciudad en la civilización occidental (Madrid:Alianza, 2007). 
que se sustentaba en la voluntad de sus habitantes, en el gobierno y en la utilidad que producía. ${ }^{5}$

El caso de las ciudades trasladadas o abandonadas en el Nuevo Reino de Granada evidencia que era mucho más fuerte el ideal de ciudad como cuerpo político, puesto que las condiciones materiales de los asentamientos eran adversas y no contaban con un desarrollo urbanístico sólido. Es decir, la ciudad definida por la civitas era la que permitía su movilidad y continuidad en el tiempo. ${ }^{6}$

En este artículo el propósito principal es conocer los argumentos esgrimidos por quienes estaban a favor del traslado de la ciudad de Santiago de las Atalayas y por quienes defendían su permanencia, e identificar los cambios o continuidades en las ideas, o representaciones políticas, que definían lo que era la ciudad y sus posibilidades de movilidad.

El traslado de Santiago de las Atalayas es relevante para comprender las dinámicas que se tejían en torno a la decisión de cambiar el lugar de asentamiento de una comunidad y porque revela el imaginario que sus habitantes y las autoridades tenían sobre lo que era y debía ser la ciudad. Este caso es algo excepcional, porque se cuenta con el expediente completo que permite ver las posiciones encontradas de los vecinos que residían en ella, hubo quienes se adhirieron fácilmente al traslado, así como quienes defendieron el sitio antiguo y procuraron su permanencia. La contra posición de estos bandos y argumentos exhibe cómo fue asumido e interpretado el ideal de ciudad, así como la concreción de las órdenes emanadas por la Corona para guiar el poblamiento y las constantes tensiones entre diferentes niveles del poder.

El caso de Santiago de las Atalayas, muy rico en información, sirve para ampliar la compresión del momento coyuntural por el que atravesaron otros centros urbanos, sobre todo, cuando no había unanimidad en la decisión de traslación. Esta documentación contiene un debate político en torno a la definición de lo que era la ciudad en el período colonial y la forma como fue entendida por sus habitantes, así como el papel desempeñado por las autoridades de la gobernación y de la Audiencia en la administración a una escala local o virreinal. La comparación y contrastación de la información de este expediente con otros informes de la época permiten poner en contexto la situación por la que atravesaba la ciudad, entender los argumentos expuestos en el pleito e interrogarlos a la luz de los posibles intereses de cada grupo.

El traslado, abandono o refundación de ciudades y villas en América era una realidad y hasta una condición para su perpetuidad. El estudio de esta problemática permite comprender el proceso de conquista del territorio y de la población nativa, la consolidación del poblamiento europeo y las crisis en el desarrollo urbano y en la territorialización del poder monárquico a escalas locales.

5. Giovanni Botero, Delle cause della grandezza delle citta (Roma: Giovanni Martinelli, 1588).

6. Yirla Marisol Acosta Franco, Mudanzas y desasosiegos de los cristianos: ciudades móviles del Occidente del Nuevo Reino de Granada, 1509-1611 (Medellín: Instituto para el Desarrollo de Antioquia, 2015). 
La investigación de Alain Musset, Ciudades nómadas del Nuevo Mundo, muestra el problema de la movilidad urbana como una constante que atravesó el período colonial. Además, expone las incidencias que tuvieron el imaginario sobre la ciudad, la dialéctica de lo sano y lo malsano sobre la geografia y las catástrofes naturales en determinaciones sobre la movilidad. En palabras de Musset, los traslados constituyeron una "etapa obligada" en el largo proceso de urbanización americana, en el que las ciudades o las villas migraron para encontrar solidez en sus asentamientos. ${ }^{7}$

Los movimientos realizados por los centros urbanos también demuestran la especificidad del poblamiento americano, las condiciones físicas y naturales, la voluntad de oficiales y vecinos que se vio reflejada en la fundación y en la perpetuidad de las mismas, pues muchas ciudades dependían del capricho de las autoridades y fueron consideradas como ciudades portátiles. ${ }^{8}$ El fracaso urbano estuvo ligado a causas como la hostilidad de los grupos indígenas, el acceso a recursos para el sostenimiento de la población, la creación de economías sólidas y las condiciones ambientales de los lugares de asentamiento. ${ }^{9}$

En el Nuevo Reino de Granada y Popayán durante los siglos XVI y XVII se pueden contar más de 45 casos de ciudades y villas trasladadas o abandonadas, una cifra que, con toda seguridad, puede ser superior dada la reducida información que se tiene al respecto. ${ }^{10}$ En estos casos, el factor determinante para la movilidad fue la búsqueda de recursos, esencialmente mineros, lo cual llama la atención sobre la voluntad política de autoridades locales y vecinos para preservar los centros urbanos pese a su trashumancia.

Es importante notar que en el escenario del siglo XVIII en los centros urbanos se evidenciaban comportamientos e ideales que reforzaron la idea de ciudad en términos civiles, políticos y económicos, puesto que las diferencias entre la población generaron una división entre grupos que luchaban por sus intereses, entre los que sobresalían quienes conformaban el cuerpo político que debía velar por el adecuado sostenimiento de las ciudades. El funcionamiento de la sociedad en torno a la ciudad evidencia la importancia de esta para ciertas personas que procuraron mantener una posición social privilegiada, lo que generó segregación en ciertos sectores y dificultó el proceso de traslado, ya que, como lo señaló Musset, en la medida en que los grupos sociales se distinguían unos de otros "era más difícil hacer coincidir todas las opiniones y tomar, sin atizar graves conflictos internos, las medidas que fuesen necesarias según el punto de vista de algunos", ${ }_{11}$ algo notorio en Santiago de las Atalayas.

7. Alain Musset, Ciudades nómadas del Nuevo Mundo (México: Fondo de Cultura Económica, 2011) 137.

8. Thomas Calvo, "Una adolescencia americana. Las ciudades del Nuevo Mundo hispánico hasta 1600", Historias 71 (2008): 101-132.

9. Salvador Álvarez, "Poblamientos y abandonos en la frontera septentrional novohispana. Los pueblos de hacienda del antiguo valle de San Bartolomé", Trace 43 (2003): 38-55.

10. Acosta, "Traslados y abandonos de ciudades".

11. Musset, Ciudades nómadas 251. 
El estudio del traslado de Santiago de las Atalayas pone de relieve el fracaso de cierto proyecto de poblamiento que permitiría la consolidación de la conquista y la expansión de los dominios imperiales, por un lado; y la puesta en escena de una estrategia para preservar esos mismos objetivos y garantizar el control territorial y de la población, por el otro. Hablar de movilidad urbana es una paradoja, porque en un principio se tiende a pensar en esta como un lugar de estabilidad y arraigo en donde se llevaba a cabo un proyecto de permanencia y vecindad. ${ }^{12}$

Una decisión de este tipo no era fácil de tomar y, aunque en la ejecución de un traslado se manifestaban las posturas de poder, también permitía "corregir los errores posibles de una primera fundación y de repensar, al mismo tiempo, el asentamiento, el espacio urbano, su organización social y sus relaciones con el entorno". ${ }^{13}$ Sin embargo, no todos los miembros de la ciudad tenían las condiciones económicas para adelantar la reconstrucción de viviendas y patrimonios en un nuevo lugar, lo cual se asoció a la posición social que se había logrado en el antiguo sitio y que podía ponerse en entredicho en el nuevo lugar, pese a que la relativa facilidad para cambiar de sitio obedecía, por lo general, a que las ciudades eran construidas en madera. ${ }^{14}$ De esta manera, la coyuntura del traslado, por la crisis que albergaba, evidencia la complejidad de la sociedad.

\section{El traslado de Santiago de las Atalayas, 1780}

La ciudad de Santiago de las Atalayas fue fundada en 1588 por el capitán Pedro Daza, quien salió de la ciudad de Tunja para poblar la provincia de Cusiana y Achagua. ${ }^{15}$ Aprovechó la mano de obra indígena y el establecimiento de haciendas para su sostenimiento. Efectuó un traslado en el siglo XVII para facilitar las condiciones de acceso al agua, ${ }^{16}$ pues en 1640 la ciudad producía doce mil varas de algodón por año, seis mil cabezas de cerdo, cinco mil de ganado vacuno y dos mil arrobas de pescado. ${ }^{17}$ Gracias a estas condiciones en el siglo XVIII se convirtió en la capital de la provincia de la Atalaya más conocida como los Llanos, en los actuales departamentos de Arauca y Casanare.

Para mediados de esa centuria, la provincia tenía cinco ciudades: Santa Rosa de Chire, San Josef de Pore, Santiago de las Atalayas, San Juan de los Llanos y San Martín del Puerto; así como pueblos de misión. Santiago de las Atalayas era la ca-

12. Manuel Lucena Giraldo, "La fundación de América a través de su historia urbana", Memorias de ciudad. Urbanismo y vida urbana en Iberoamérica colonial (Bogotá:Alcaldía Mayor de Bogotá, 2008) 19-36.

13. Musset, Ciudades nómadas 31.

14. Alain Musset, "Abandonos y traslados de ciudades en Hispanoamérica. Historia en el olvido, memoria de los lugares", Trace 43 (2003): 25-37.

15. Andrés Castro Roldán, "Santiago de las Atalayas: una ciudad de la frontera en el Nuevo Reino de Granada (XVI-XVIII)”, Fronteras de la Historia 12 (2007): 301-339.

16. "Reparo y traslado de Santiago de las Atalayas", Santiago de las Atalayas, 1676-1800. AGN, Bogotá, Colonia, Poblaciones Boyacá, t. 1 bis, doc. 1, ff. 1r-24v.

17. Castro 321. 
beza de gobernación, contaba con 400 vecinos, tenía iglesia de "maderos, cubierta de paja o palma, pero con buenos ornamentos y alhajas". Su curato comprendía a Surimena, Casimena, Upamena, Chameza, Labranzagrande, Pisva, Paya y Santa Bárbara, con la ciudad poblada de San Joseph de Cravo. ${ }^{18}$

Un informe del gobernador Villavicencio, en 1789, resaltó que, aunque San Juan de los Llanos y San Martín de Puerto pertenecían a esa jurisdicción, su gobierno lo tenía la Real Audiencia como consecuencia del abandono por parte de sus gobernadores, que no la visitaban por el impedimento de la geografia. ${ }^{19}$ Para la fecha, Santiago de las Atalayas contaba con las parroquias de Zapatoza, San Pedro y Taguana.

El proceso jurídico de más de veinte años para autorizar el traslado evidencia el pleito entre los vecinos de Santiago de las Atalayas y los de Barro Blanco, lugar a donde se mudaron algunos habitantes después de un incendio que, según testimonios, destruyó gran parte del centro urbano. Este pleito se dio porque no todos los vecinos se trasladaron y quienes se quedaron en el lugar de las Atalayas defendieron su posición y entorpecieron la mudanza.

El motivo principal para el movimiento de la ciudad fue el incendio del año de 1777, el traslado se dio en 1780 bajo la autorización del gobernador don Josef Caycedo y desde entonces buscaron la licencia de la Real Audiencia. No se conocen las causas del incendio. Sin embargo, en enero de 1790, en un informe presentado por el cabildo de Santiago de las Atalayas fue señalado que eran muchos y graves los incendios que afectaban a toda la provincia en el tiempo de verano, algunos de ellos fueron: el de Santiago de las Atalayas en 1777, “en el año de ochenta y tres la parroquia de Nunchia, en el de ochenta y cinco la ciudad de Pore, en el de ochenta y siete la parroquia de Taguana y en el de ochenta y nueve el que padeció el pueblo de Porcote". ${ }^{20}$

En esta situación particular es preciso considerar las causas de los incendios, pues si bien se dijo que ocurrían en el tiempo de verano, en 1790 el gobernador Villavicencio indicó que estos eran cometidos de manera periódica por los indios que rodeaban la provincia de los Llanos. ${ }^{21}$ Esto permite reflexionar sobre otros asuntos que aquejaban a la ciudad y a la administración de la provincia gracias a la permanencia de población nativa insumisa y al constante temor de una invasión extranjera por la ubicación fronteriza.

En el proceso, para el año de 1795 a las justificaciones ofrecidas como causas del traslado se sumó la búsqueda de una cura para las enfermedades que padecían sus

18. Basilio Vicente de Oviedo, Cualidades y riquezas del Nuevo Reino de Granada (Bogotá: Imprenta Nacional, 1930) 222-229.

19. "Estado de la provincia de los Llanos", Santa Fe, 1789. AHN, Sevilla, Colección Documentos de Indias, Diverso-colecciones 32, n. 40, f. 2r.

20. "Santiago de las Atalayas: licencia para construir Iglesia”, Santa Fe, 1798. AGN, Bogotá, Colonia, Miscelánea, t. 67, doc. 113, f. 956v.

21. AHN, Sevilla, Colección Documentos de Indias, Diversos-colecciones 32, n. 40, ff. 3r-3v. 
habitantes por las pésimas condiciones del paraje original. ${ }^{22}$ Para la fecha, aún no se contaba con la resolución de la Audiencia por la oposición que representaban los vecinos que permanecieron en el antiguo lugar.

La oposición estuvo encabezada por el cura de la ciudad, don Alejandro Zerrano, que argumentó haber sido nombrado para la ciudad de Santiago de las Atalayas y no para el sitio de Barro Blanco, por lo que emprendió la construcción de una ramada para oficiar la misa en las Atalayas. Además, procuró mover en reiteradas ocasiones a la misma ciudad. ${ }^{23}$ Los cabildantes Thoribio Fernández, Marcelino de Roa y Miguel Fernández expresaron las incomodidades que sufrían los vecinos por los intentos de traslación del cura Zerrano, que propuso reedificar la ciudad en diferentes parajes. El primero era en la reducción de San Nicolás de Buena Vista en donde el corregidor del río Meta tenía congregados a los indios de misión, el segundo era en el pueblo de indios Chamezas y el tercero lo constituía el pueblo de Sabana Alta en donde el cura permaneció un tiempo. ${ }^{24} \mathrm{Al}$ ver la imposibilidad de trasladar la ciudad a uno de esos lugares, en especial por la oposición del corregidor y de los vecinos, decidió regresar al antiguo sitio de la Atalaya.

Es preciso llamar la atención sobre el hecho de que el cura procurara mover la ciudad a los pueblos de indios, esto puede reflejar un interés por el aprovechamiento tanto para la construcción de un nuevo lugar como por la presencia misma de los indios, a quienes intentó quitar un hato de ganado para trasladarlo a la cofradía de la ciudad. ${ }^{25}$ Es de resaltar el hecho de que el cura pusiera en entredicho un traslado llevado a cabo por vecinos, cabildo y gobernador y, no obstante, se adjudicara cierta autoridad para efectuar los mismos movimientos. Lo que resulta crucial es ver que cada una de estas propuestas estaba dirigida a la ocupación y usurpación de los pueblos de misión.

El 10 de febrero de ese mismo año, el cabildo presentó un resumen de las circunstancias que habían rodeado el traslado y expuso varias razones que justificaban el movimiento, asimismo solicitó la confirmación de la Audiencia. Entre sus motivaciones resaltó la enfermedad constante que padecían sus habitantes y comerciantes, tanto que se le llamaba "sepultura de forasteros". La resolución del traslado estuvo en manos del cabildo que presidió en el año de 1780, en la posición que asumió el gobernador don Jossef Caycedo y en la determinación del cura Josef de Arteaga: "que no menos propendía al beneficio común de sus feligreses y al de liberarse de las diarreas continuas calenturas que padecía y tenía padecidas en el espacio de un año", quienes favorecieron la mudanza al sitio de Barro Blanco en la margen del río Chitamena. ${ }^{26}$ Fue convocada la mayor parte de los vecinos

22. "Santiago de las Atalayas: traslación", Santiago de las Atalayas, 1788. AGN, Bogotá, Colonia, Poblaciones Boyacá, t. 1 bis, doc. 11, f. 162r.

23. AGN, Bogotá, Colonia, Poblaciones Boyacá, t. 1 bis, doc. 11, ff. 162r-162v.

24. AGN, Bogotá, Colonia, Poblaciones Boyacá, t. 1 bis, doc. 11, ff. 165r-165v.

25. AGN, Bogotá, Colonia, Poblaciones Boyacá, t. 1 bis, doc. 11, f. 165v.

26. AGN, Bogotá, Colonia, Poblaciones Boyacá, t. 1 bis, doc. 11, f. 164r. 
a dicho cabildo, en especial los que llevaban las "cargas de la república" y quienes respaldaron la determinación de la mudanza.

En el sitio de Barro Blanco se procuró la reedificación de la ciudad, "construyendo en él iglesia capaz y decente para celebrar los divinos oficios aunque de la construcción que el país ofrecía al punto construyendo también casa de cura, cabildo y dos cárceles reponiendo en cada una destas obras los adornos que les corresponde y el incendio había reducido a cenizas". ${ }^{27}$

\section{Restitución "a fuego y sangre"}

La defensa que adelantó el cabildo que residía en Barro Blanco exaltó el bienestar común de la población, que se manifestaba en la robustez de los niños al no enfermarse como en el anterior sitio, una característica que es posible rastrear hasta las ordenanzas de poblamiento que estipulaban la forma de conocer los lugares a partir de la condición de sus habitantes; en el capítulo 34 de estas disposiciones se apuntó que la salud del sitio "se conocerá en la copia que huviere de ombres viejos y moços de buena complisión dispusicion y color y sin enfermedades". ${ }^{28}$ Aunque en los informes que componen el expediente del traslado no hay una alusión directa a las ordenanzas de poblamiento, es posible identificar la permanencia de sus postulados en el imaginario de la población tanto porque estas daban la directriz para el poblamiento como porque encerraba un ideal de sanidad que ya estaba presente en las personas.

Ese bienestar era el que pretendía destruir el cura Zerrano, pues este, según el regimiento, reunió a la población y manifestó la ilegitimidad del cabildo, el cual no debía ser respetado "por no estar esta ciudad fundada en el lugar y sitio de la Atalaya que aquellos vecinos debían haberla restituido a él a fuego y sangre, que no se debe celebrar en esta santa iglesia el santo sacrificio de la misa, y que su curato no es esta ciudad sino la de la Atalaya y que por lo mismo no tiene obligación de residir en esta ciudad". ${ }^{29}$ Aunque este discurso, que dice el cabildo había sido pronunciado por el cura, puede entenderse como un llamado al irrespeto o a la desobediencia y resulta temerario en cuanto que muestra en esa lógica cómo debía defenderse la ciudad, evidencia una paradoja entre los elementos que sostenían el ideal de ciudad. Pareciera que lo importante era el lugar de origen del centro urbano y no la comunidad política que se representaba mediante el cabildo, lo cual permite, a su vez, conocer a la población o el grupo social que sí estaba representando a quienes llevaban "las cargas de la república".

Hace falta conocer la posición de los habitantes que se quedaron a residir en el antiguo sitio, pues estos claramente no estaban siendo representados por el cabildo

27. AGN, Bogotá, Colonia, Poblaciones Boyacá, t. 1 bis, doc. 11, f. $164 \mathrm{v}$.

28. Transcripción de las ordenanzas de descubrimiento, nueva población y pacificación de las Indias dadas por Felipe II, el 13 de julio de 1573, en el Bosque de Segovia, según el original que se conserva en el Archivo General de Indias de Sevilla (Madrid: Ministerio de Vivienda, 1973) 34.

29. AGN, Bogotá, Colonia, Poblaciones Boyacá, t. 1 bis, doc. 11, ff. 166r-166v. 
que tenía lugar en Barro Blanco. Al parecer, después de las palabras pronunciadas por el cura muchos de los vecinos importantes del pueblo se ausentaron de Barro Blanco para avecindarse en otras poblaciones y mantener la quietud en sus familias, con lo que la ciudad se vería despoblada en el largo y complejo proceso de legitimación del traslado.

\section{Ideales de ciudad, representaciones colectivas}

Durante el proceso las partes tuvieron representación de sus procuradores, los cuales alegaron diferentes causas y circunstancias para defender sus posiciones. Entre ellas, se aludió a las condiciones de sanidad de ambos lugares, a la facilidad del tránsito y del comercio, así como a la calidad e importancia de los vecinos. El procurador Luis Lamprea argumentó, en nombre de los vecinos que residían en Barro Blanco, en mayo de 1798, lo siguiente para conseguir la aprobación por parte de la Real Audiencia:

es tan público lo enfermo y pernicioso del temperamento en el sitio de las Atalayas, donde estaba antiguamente radicada la ciudad, que no habrá sujeto en todo este reino que no tenga noticia de su perversidad: allí apenas comenzaban a vivir los hombres cuando los conducían para el sepulcro, apenas llegaban a la cuna cuando se hallaban insultados de la vehemente epidemia de calenturas que les eran inseparables por el resto de sus días, hallándose inhábiles e inválidos los que no espiraban en su infancia. El único arbitrio que hallaron aquellos infelices moradores para redimirse de una temprana muerte fue el mantenerse retirados del asiento de la ciudad, de forma que apenas se congregaban el día festivo para oír misa y se marchaban tan aceleradamente que ni aún desensillaban sus cabalgaduras por no retardarse ni un momento más de lo preciso. ${ }^{30}$

Esto permite pensar en el hecho de que sus habitantes vivieron por más de dos siglos en un ambiente adverso a su salud y que tan solo aprovecharon la destrucción de la ciudad como consecuencia del incendio para plantearse este tipo de problemas y buscar una solución con su traslado. En el informe que remitió el gobernadorVillavicencio, en 1789, apuntó que el temperamento de toda la provincia no era igual, pues dependía de la cercanía a la sierra o de las condiciones de las tierras bajas, pero en general era "regularmente sano" con "las circunstancias ventajosas a formar un clima benigno". ${ }^{31}$ Por el contrario, Basilio Vicente de Oviedo precisó a mediados de siglo que el lugar de la ciudad de Santiago de las Atalayas en las riberas de río Aguamena era retirado y "su temperamento algo enfermo". ${ }^{32}$

Las diferencias entre opiniones reflejan el interés de cada participante y lo que procuraba conseguir con su argumentación. Al respecto, Musset sostiene que el discurso de lo sano y lo malsano se fundaba, de manera directa o indirecta, sobre

30. AGN, Bogotá, Colonia, Poblaciones Boyacá, t. 1 bis, doc. 11, ff. 177r-177v.

31. AHN, Sevilla, Colecciones Documentos de Indias, Diversos-colecciones 32, n. 40, f. 2r.

32. De Oviedo 223 
los textos de Hipócrates y Galeno: “el calor y la humedad, según los médicos y los cosmógrafos, ejercían una influencia nefasta, no solo sobre la salud sino también en los comportamientos individuales y colectivos". ${ }^{33}$ Más que notar de dónde provenían las ideas sobre las consideraciones de los lugares, porque es notorio como lo señalé anteriormente que en las ordenanzas de poblamiento se definían ciertas condiciones para establecer la sanidad de los sitios de asentamiento y garantizar la prosperidad de los mismos, es necesario advertir cómo se usaron esas condiciones fisicas para reforzar argumentos en pro de una determinación de la Audiencia que favoreciera los intereses de una comunidad.

Algo revelador que sostuvo el procurador fue la marcada ausencia de los vecinos en el centro urbano por la situación malsana, lo cual da lugar a cuestionar un despoblamiento y la nueva aglomeración en Barro Blanco. No debe perderse de vista que a finales del siglo XVII la ciudad presentó un informe en el que evidenció el despoblamiento y lo atribuyó a factores económicos, a que los vecinos estaban en los términos de la ciudad atendiendo sus haciendas. ${ }^{34}$ Es decir, la ausencia de vecinos estuvo ligada a factores que no necesariamente estaban determinados por lo climático; Andrés Castro señala que la vecindad de los habitantes era compartida con la ciudad de Tunja, en donde residían gran parte del año. ${ }^{35}$ Asimismo, esto muestra un esfuerzo por la conservación de la ciudad a pesar del marcado índice de despoblamiento, ya sea por la preservación del título y del estatus que se extendía a sus habitantes o por la garantía de una cultura urbana, civil y política. Cabe anotar que la alusión al hecho de que los vecinos solo estaban en la ciudad en los días festivos para oír misa da cuenta de la importancia de la Iglesia y la misa como garante del núcleo y la cultura urbana.

Es importante advertir el carácter retórico de los argumentos, pues en una disputa que buscaba favorecer los intereses de cierta población era preciso resaltar los rasgos principales que fortalecieran las razones que ayudaran en la consecución de los propósitos de cierto grupo. En ese caso, el testimonio del procurador estaba orientado a identificar un problema con las condiciones naturales que imposibilitaba el crecimiento y prosperidad de la población. La dialéctica de lo sano y malsano se usó con mucha frecuencia para justificar las decisiones que se tomaban al interior de las ciudades, exponer sus necesidades y señalar el fracaso o éxito de los centros urbanos.

El procurador agregó a esta descripción un lamento por el estado en el que se encontraba la capital de los Llanos; dijo:

Por su antigüedad debería ser una de las más populosas pero por sus pésimas calidades era la más ruin despreciable; porque apenas se denominaba tal por quien sabía que se le había concedido

33. Musset, Ciudades nómadas 101.

34. "Santiago de las Atalayas: conquista de sus indios", Santiago de las Atalayas, 1673. AGN, Bogotá, Colonia, Caciques e Indios, t. 16, doc. 10, f. 341v; Acosta, “Traslado y abandono de ciudades” 96.

35. Castro 307. 
semejante título no porque su apariencia, edificios, ni habitantes dieran otra idea que de una cabaña en donde habían acogido los vivientes más desvalidos y atrasados. Allí jamás se encontraba otra gente que los que no tenían si quiera un caballo para poder retirarse de los umbrales del sepulcro: porque los que tenían algunas proporciones continuamente residían en sus estancias o haciendas y miraban con tanto desprecio el adelantamiento de aquella capital. ${ }^{36}$

Es interesante la forma como Luis Lamprea justificó el abandono de la ciudad por parte de los vecinos que le debían dar el sustento, lo que minimizó el interés económico de cada uno de estos hacendados. Asimismo, articuló la antigüedad con la estructura urbana, algo que, unido a lo que adujo el cabildo, demuestra una prevalencia de lo urbano y lo físico sobre lo político o civil. Es decir, en la ciudad no vivían sus principales vecinos por las condiciones materiales y salubres de la misma, y sus edificios tampoco eran consistentes con el título que ostentaba. Para complementar esta información, en 1789 el gobernador Villavicencio señaló que Santiago de las Atalayas tenía mil vecinos y comprendía las parroquias de Zapatoza, San Pedro y Taguana. Según el gobernador, esta cifra era reducida en relación con el territorio que ocupaba por lo que la consideraba desierta. ${ }^{37}$ Sin embargo, no hay precisión sobre cuántos habitantes residían en la ciudad y su estatus, cuántos en el nuevo sitio de Barro Blanco y cuántos en las parroquias.

Después de exponer las afecciones de índole material y natural, el procurador pasó a señalar la calidad de los vecinos y a demostrar la baja condición de los pobladores del antiguo sitio para resaltar la comunidad sobre la que recaía la obligación y necesidad, al mismo tiempo, de sostener la república. Lamprea insistió en que los habitantes eran "unos sujetos de tan conocidas proporciones que todos ellos no han podido refaccionar los ranchos o tujurios de paja de que estaba adornada aquella población y claman para que a expensas de los que se han retirado se reedifiquen. Ellos están sumergidos en tan abatidas miserias que por eso no han tenido arbitrios para separarse de aquel recinto venenoso". ${ }^{38}$

Esas características divulgan los medios económicos de las personas que permanecieron en las Atalayas, lo que muestra la dificultad que suponía el traslado y la reedificación de sus viviendas, si es que no habían sido afectadas por el incendio. Además, el procurador inquirió sobre la conveniencia de que semejante título de ciudad recayera en una población poco educada de la cual solo cuatro personas podían firmar. Elevó las siguientes preguntas para generar preocupación en quienes debían aprobar la solicitud:

A vista de estas circunstancias tan despreciables ¿Será decente al Estado o a la patria que se le conceda el nombre de ciudad a unos sujetos que habitan una población que en vez de darle lustre y nombre al reino será el objeto de la censura? o por el contrario ¿Será más decoroso que el

36. AGN, Bogotá, Colonia, Poblaciones Boyacá, t. 1 bis, doc. 11, ff. 177v-178r.

37. AHN, Sevilla, Colecciones Documentos de Indias, Diversos-colecciones 32, n. 40, f. 2r.

38. AGN, Bogotá, Colonia, Poblaciones Boyacá, t. 1 bis, doc. 11, f. 178r. 
anterior título de ciudad se conserve y permanezca en el congreso que los caballeros y personas de más distinción y sensatez, de unánime acuerdo y con autoridad de su gobernador eligieron, poblaron y han fomentado en un sitio el más benéfico para la salud y más acomodado para el comercio? Yo desde luego no juzgo que debe merecer la aprobación superior la nueva fundación hecha por los más útiles y provechosos ciudadanos en el sitio de Barro Blanco, sino que deben ser con particularidad distinguidos por un servicio tan ventajoso y recomendado que han ejecutado a favor del estado de la humanidad y de su patria. ${ }^{39}$

La exposición de Luis Lamprea es coherente y ofrece los argumentos necesarios para orientar la resolución que buscaban los vecinos de Barro Blanco. Su retórica permite ver la concepción que se tenía acerca de lo que era y debía ser la ciudad a partir de ese imaginario común en términos de lo político, y también de los beneficios que debía generar en lo económico. Es visible la selección de un grupo que sería el que definiría la comunidad política que debía preservar el ideal de ciudad y que, de unánime acuerdo, eligieron un lugar para poblarlo tal y como lo define la civitas. El cabildo era el cuerpo político que representaba y defendía los intereses particulares de un grupo que al final de cuentas era el que sostenía a la ciudad, ${ }^{40}$ pues como lo apuntó Castro: la historia de Santiago de las Atalayas está ligada a la de "sus encomenderos y tratantes de indios, organizados en clanes de familias a través del poder heredado que ejercieron como poseedores de indios, terratenientes, cabildantes, y tenedores de oficios de gobierno". ${ }^{41}$

Para finalizar la demostración planteada en su discurso, el procurador enunció el futuro que podría esperarse dependiendo de la decisión que tomara la Audiencia, sostuvo que si no se otorgaba la autorización la ciudad solo se encontraría en los libros de antigüedades, pues su abandono era inminente. ${ }^{42} \mathrm{El}$ panorama planteado fue el peor de los escenarios, el abandono definitivo de la ciudad y el fracaso del proyecto de conquista, poblamiento y república. Lamprea dedicó sus últimas líneas a responder una pregunta que puede surgir a cualquier lector, contemporáneo o de época, en especial del fiscal encargado de revisar el caso para definir lo conveniente respecto del traslado: ¿por qué se fundó una ciudad en un lugar con tan malas condiciones de sanidad para la población y duró tanto tiempo? Para él, la decisión de fundar una ciudad allí obedeció a la necesidad de los primeros conquistadores que procuraban una defensa de los ataques indígenas, condición que había cambiado para su momento. ${ }^{43}$

Sin lugar a dudas, la explicación remite a la funcionalidad que tuvieron las ciudades en la etapa de conquista y pacificación indígena; sin embargo, no debe olvidarse

39. AGN, Bogotá, Colonia, Poblaciones Boyacá, t. 1 bis, doc. 11, ff. 178v-179r.

40. Manuela Cristina García Bernal, “Sobre cabildos y élites en Yucatán”, Mesoamérica 21.39 (2000): 418-424; Manuela Cristina García Bernal, "Las élites capitulares indianas y sus mecanismos de poder en el siglo XVII”, Anuario de estudios americanos 57.1 (2000): 89-110.

41. Castro 303.

42. AGN, Bogotá, Colonia, Poblaciones Boyacá, t. 1 bis, doc. 11, f. 179v.

43. AGN, Bogotá, Colonia, Poblaciones Boyacá, t. 1 bis, doc. 11, f. 180r. 
el carácter simbólico y el significado que reunía la idea de fundar una ciudad. No solo era el lugar desde donde se repelían los ataques indígenas o desde donde emanaban las campañas de expansión territorial. La ciudad era la república misma, ese espacio en donde se podía desarrollar una vida perfecta y la comunidad podía tener una representación y legitimidad a instancias de un poder central como la monarquía. La tesis sostenida por Lamprea ofrece una visión sobre ese imaginario que permite concebir la ciudad a partir de su función, al tiempo que muestra un cambio en el contexto mismo que rodeaba a los centros urbanos, así como una adecuación del discurso de lo sano y lo malsano a las nuevas condiciones y a las obligaciones de sus vecinos.

Es claro que los argumentos ofrecidos hasta el momento aludían a la situación particular de Santiago de las Atalayas; mas el informe remitido por el cabildo de la ciudad en enero de 1790 contradecía esa idea de que los indígenas estaban retirados y no existía la obligación de permanecer en un lugar para garantizar el hecho de la conquista. En ese informe se indicó que mediante cuadrillas de indígenas que rodeaban la provincia de los Llanos, atacaban, robaban e incendiaban de forma periódica. $^{44}$

Es preciso enunciar que, si bien las condiciones no eran las mismas del siglo XVI, la provincia de los Llanos por su condición fronteriza tenía una constante amenaza, según el gobernadorVillavicencio y el virrey Mendinueta, pues por sus ríos podría tener lugar algún tipo de invasión extranjera, sobre todo al momento de la guerra con los ingleses, de la pérdida de Trinidad y del peligro en la Guyana. ${ }^{45}$ Con esto, la situación de conquista de la población nativa y la función de la ciudad como defensa de los ataques indígenas cambió por un panorama de una región de frontera externa que debía preservarse para garantizar la estabilidad al interior del Nuevo Reino y el dominio de la monarquía en esa región. ${ }^{46}$ Esta situación de alarma ante una invasión de potencias extranjeras estuvo presente en los gobernadores y capitanes de la provincia desde mucho tiempo atrás; en el siglo XVII con la fundación de San Martin y Santa María de la Rosa se buscó garantizar cierta defensa en la región y evitar el ingreso de posibles enemigos. ${ }^{47}$

44. AGN, Bogotá, Miscelánea, t. 67, doc. 113, ff. 955r-960v.

45. Desde el informe del gobernador Villavicencio, en 1789, se presentó como de alto riesgo la amenaza de una invasión, lo que llevó a la creación de un gobierno militar en 1798 a cargo del capitán don Remigio de Bobadilla. "Estado de la provincia de los Llanos", Santa Fe, 1797.AHN, Sevilla, Colección Documentos de Indias, Diverso-colecciones 32, n. 40, ff. 1r-6v; "Conspiraciones internas en los Llanos", Santa Fe, 1797. AGS, Simancas, Secretaría del Estado y Despacho de Guerra, legajo 7068, 31, ff. 1r-8v; "Sobre creación gobierno militar en los Llanos" Santa Fe, 1797. AGI, Sevilla, Estado 52, n. 47, ff. 1r-2v; "Remigio Bobadilla. Gobierno Llanos", Santa Fe, 1798-1799. AGS, Sevilla, Secretaría del Estado y Despacho de Guerra, legajo 7087, 8.

46. AHN, Sevilla, Colección Documentos de Indias, Diversos-colecciones 32, n. 40, ff 1r-6v; AGS, Simancas, Secretaría del Estado y Despacho de Guerra, legajo 7087, 8.

47. "Fundación de Santa María de la Rosa", San Salvador del Puerto de Casanare, 1676.AGN, Bogotá, Colonia, Poblaciones Boyacá, t. 2, doc. 4, ff. 69r-77v. 
En respuesta a la comunicación de Luis Lamprea, la representación de los vecinos de las Atalayas por parte del procurador Juan José Caballero estuvo encaminada a exhibir la ilegitimidad del proceso de traslado, ya que fue autorizada por el gobernador don Josef Caycedo y este no poseía la facultad para tal determinación. Indicó que el principal motivo expuesto para el traslado había sido la destrucción de la ciudad a causa del incendio, pero este solo había afectado a la tercera parte de la población y la mudanza se efectuó contra la voluntad de la mayoría de los vecinos, quienes se oponían porque los alcaldes de ese año y el cura Miguel Arteaga tenían sus haciendas en Barro Blanco. ${ }^{48}$

A esto se sumó el hecho, un poco reiterado en todos los informes, de que "tan enfermizo es el clima de la ciudad de Santiago de las Atalayas como el de Barro Blanco", pues solo las dividía cinco leguas y el caudaloso río Cusiana que, además, dificultaba el tránsito de los pobladores (Figura 1). Mencionó que la misma condición se hacía extensible a todos los Llanos y que:

Si esto fuera causa bastante para trasladar la ciudad sería necesario destruirlas todas y abandonar un país que ofrece las mayores comodidades y sobre cuyo fomento se trata en estos tiempos con tanto acaloramiento / es verdad que el buen temperamento debe influir para el establecimiento de nuevas ciudades sino como una causa absoluta a lo menos como concurrente, pero yo no creo que lo sea para destruir la ya edificada y trasladarla a otro sitio. ${ }^{49}$

Citó en su exposición la resolución que el 14 de octubre de 1784 había proferido el fiscal Andino en la cual decía que:

la traslación no podía subsistir por ser hecha por autoridad privada de un corto número de vecinos quedándose los demás en el antiguo sitio, que la causa del incendio y enfermedad nunca se había calificado y que solo se había tomado por pretexto siendo la causa verdadera el interés de tener a mano sus hacienda por cuya razón era de sentir el que se desaprobase la traslación declarándola por infundada. ${ }^{50}$

Este dictamen pone en evidencia las tensiones entre diferentes niveles del poder, las decisiones tomadas por cabildos para favorecer sus intereses en una escala local y las dificultades de los miembros de la Audiencia para hacer cumplir sus determinaciones.

El despliegue de los argumentos de Caballero fue corto, se limitó a enunciar asuntos de orden jurídico. Cabe resaltar el hecho de que no negó ni procuró contradecir las condiciones naturales de las Atalayas y, mucho menos, hacerla ver como una tierra sana y prometedora en riquezas; mostró, más bien, que esta era una situación compartida en la provincia de los Llanos, lo cual no se solucionaría con el 
Figura 1. Traslado de Santiago de las Atalayas al sitio de Barro Blanco
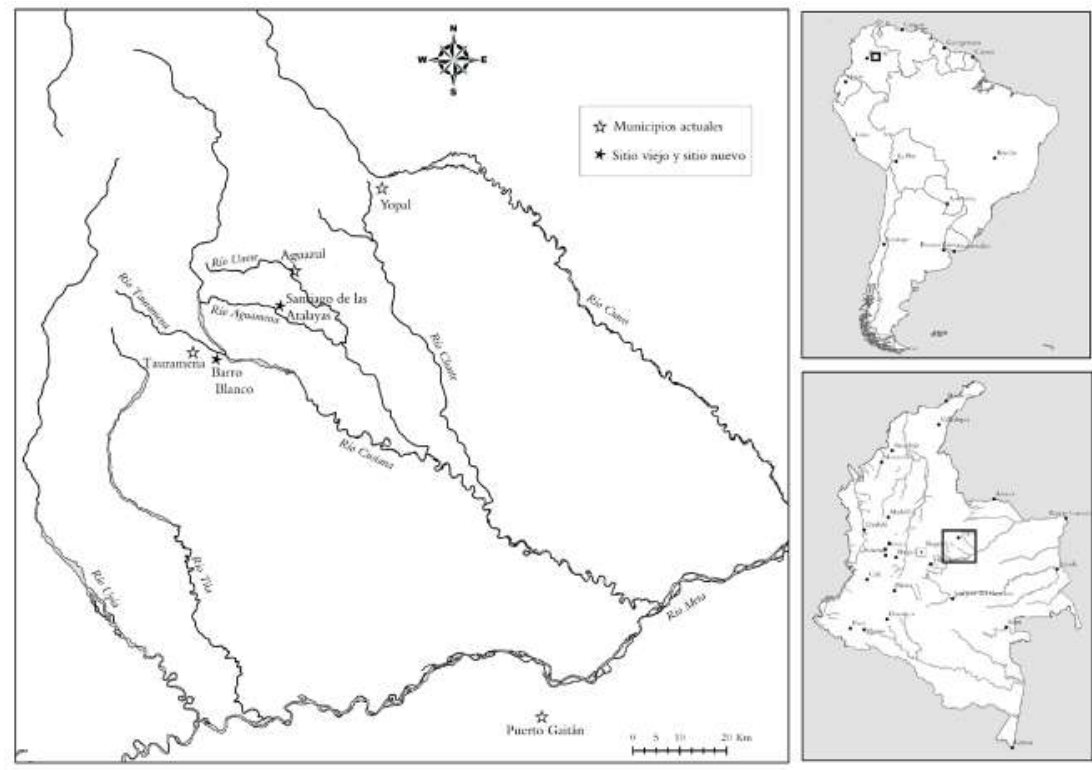

Fuente: Elaboración propia a partir de las fuentes y cartografia consultada para la elaboración del artículo.

traslado a otro sitio. También exhibió los intereses particulares de cierta población, lo que necesariamente iba en contra del bienestar común que se buscaba en la república; apoyó la idea de ciudad sustentada bajo los argumentos de comunidad y legitimidad a partir del reconocimiento de la Corona.

\section{Acudir a Cicerón o a Aristóteles para sustentar la ciudad}

La defensa de los vecinos que se asentaron en Barro Blanco orientó el discurso de una manera que deja ver una superposición de la ciudad material a la comunidad política y moral; sin embargo, no descuidó ese elemento transversal. Cuando se refirió a la calidad de los habitantes de un sitio y de otro hizo énfasis en el hecho de quiénes debían componer esa comunidad. De acuerdo con Pablo Rodríguez, la sociedad colonial consideraba que el español portaba los atributos necesarios para representar a la comunidad como regidor, y si este contribuía a la Corona con sus tributos y a la parroquia, su calidad era aún mayor. ${ }^{51}$ Es así que Lamprea expresó que en el sitio de Barro Blanco

Están unidos y congregados los sujetos hacendados, los de mayor instrucción y de mejor nacimientos, estos son los que constituyen lugar y no la recua de desvalidos, enfermos y pobres que

51. Pablo Rodríguez, Cabildo y vida urbana en el Medellín colonial, 1675-1730 (Medellín: Universidad de Antioquia, 1992) 124. 
se hallan en las Atalayas, que lejos de ser benéficos a la patria, son otras tantas cargas y petardos para la república y Estado / la gracia o merced de ciudad principalmente se concede por los méritos y buenos servicios que han ejecutado los vasallos, no a lo material del terreno o sitio se le imparte sino al congreso ilustre y distinguido, por consiguiente en este debe permanecer aun cuando por poderosas y vigentes causas se vea precisado a mudar de suelo en donde subsistir. ${ }^{52}$

Lo anterior demuestra que la comunidad, definitivamente, era la ciudad y que, aunque lo natural y geográfico afectaba el desarrollo y sostenimiento de los habitantes, esta no debía verse impedida por estas características, pues una solución podía ser el traslado, el cambio de lugar de asentamiento. Con este argumento conseguía unir dos elementos esenciales que se buscaron en el poblamiento del Nuevo Reino de Granada: la construcción de república en lugares adecuados para su sostenimiento y la perdurabilidad en el tiempo, así como la importancia de los cuerpos políticos.

No es posible dejar de lado lo que apuntó en esas primeras líneas, la segregación de cierta población que no se consideraba la idónea para formar parte de la comunidad y que en lugar de propiciar el mejoramiento de la ciudad lo impedía. Esto puede reflejar una condición que se procuraba mantener en las ciudades: la división estamental de la población, algo difícil por el elevado índice de mestizaje. Esta situación cuestiona hasta qué punto fue funcional la definición de una comunidad sumamente excluyente para el sostenimiento de los centros urbanos en la medida en que esa comunidad homogénea se fue desdibujando con el tiempo y, por el contrario, la población mestiza fue tomando fuerza y relevancia en el sostén de estas ciudades.

La tesis del procurador sobre la comunidad fue reforzada por medio de una cita de Cicerón sobre la civitas, definida como multitud de hombres que mantienen un vínculo en la sociedad. ${ }^{53}$ Por su parte, los alegatos del procurador de los vecinos residentes en el antiguo sitio de las Atalayas se fundamentaron en la tesis de Aristóteles. Sostenía que, en el "sentir del grande Aristóteles", la ciudad:

no es otra cosa que una sociedad compuesta de muchos individuos unidos con el fin de vivir tranquilamente bajo un vínculo que los obliga a procurarse recíprocamente su felicidad, jamás puede establecerse ni destruirse sin que para ello preceda el consentimiento de la suprema cabeza de la Monarquía. Esta regalía están inherentes a la corona que el soberano no puede abdicarse de ella sin despojarse de uno de sus más preciosos órganos a juicio de los más sabios publicistas. ${ }^{54}$

52. AGN, Bogotá, Colonia, Poblaciones Boyacá, t. 1 bis, doc. 11, ff. 180v-181r.

53. "Somnio Scipiones expone nil est quod in terris deo fin acceptiu quan concilia cetusque hominum jure sociasi que civitates apelastur. Frances de eclesis cathedralios cap. 4, N 33 (dice) civitas est multitud hominun societatis vinculo adun[ta] ad simil una vivendum”. AGN, Bogotá, Colonia, Poblaciones Boyacá, t. 1 bis, doc. 11, ff. 180v-181r.

54. AGN, Bogotá, Colonia, Poblaciones Boyacá, t. 1 bis, doc. 11, ff. 188r-188v. 
Ambas alusiones, apoyadas en Cicerón y Aristóteles, refuerzan la idea de ciudad como comunidad política. Sin embargo, el procurador Caballero hizo énfasis en la legitimidad que tenían los centros urbanos al ser reconocidos por el monarca y contar con las prerrogativas concedidas por la Corona, es así que los traslados debían ser autorizados por este poder superior para garantizar su perdurabilidad y no alejarse del control monárquico. Con ello, buscó desautorizar el tratamiento que los gobernadores, hasta ese momento, habían hecho con la autorización de la mudanza de la ciudad, pues de alguna manera interfería con los intereses de la Corona.

\section{Determinación del gobernador don Feliciano de Otero. Espíritu glorioso y existencial de la ciudad, respeto a la antigüedad}

Después de la exposición de cada procurador se adelantó un interrogatorio para determinar cuál de los dos sitios era el más saludable y conveniente en el ámbito económico para la reedificación de la ciudad. En los testimonios se encuentran las posiciones de quienes propendían por el traslado o la permanencia de la ciudad en las Atalayas. Es complejo dirimir el asunto para definir qué sitio era más adecuado para la población, sin embargo, tras el reconocimiento ocular practicado por el gobernador don Feliciano Otero, en 1799, se sentó una posición que ofrece otra visión sobre el asunto. En principio, el gobernador reconoció su equivocación al haber declarado en su relación de 1795 que era pertinente el traslado, pues para llegar a esta conclusión se basó en los informes de los gobernadores Josef Caycedo y Manuel de Villavicencio sin haber hecho un reconocimiento personal.

El 24 de enero de 1799 el gobernador Otero efectuó el reconocimiento de la ciudad de Santiago de las Atalayas (en el antiguo sitio) y encontró que esta había sido movida unos trescientos pasos de su sitio al primero en donde fue fundada y del que se beneficiaba de la circulación de los vientos, con aguas claras y delgadas que obtenía del río Aguamena. Además, señaló las ventajas comerciales de ese paraje por la conexión del camino de Sogamoso a través del que se comunicaban con las provincias de Tunja, Socorro y San Juan. Destacó los adelantos en materia de construcción que habían adelantado los vecinos que se quedaron en el sitio, pues tenían capilla, casa del cura, cabildo, cárceles y casas de habitación. ${ }^{55}$

Por el contrario, en el sitio de Barro Blanco las condiciones físicas y salubres estaban determinadas por un terreno disparejo y anegadizo que con la duración del invierno de ocho meses permanecía convertido en lagos y lodazales. Aunque en este sitio también se construyeron los edificios representativos y necesarios para mantener la cultura urbana, el gobernador insistió en las condiciones precarias del asentamiento que amenazaba su exterminio. ${ }^{56}$

También señaló la escasa madera para la construcción y la imposibilidad de tener cría de ganados y agricultura por las características de la tierra, pese a que se 
ha señalado que el traslado obedeció al interés de algunos vecinos por tener cerca sus haciendas. Uno de los aspectos más sobresalientes en esta descripción fue la alusión a la incomunicación del lugar, ya que estaba separado de toda sociedad por el impedimento que representaba el tránsito por el río Cusiana. Cabe destacar que para el período las condiciones comerciales de la ciudad habían caído en un franco deterioro por la desaparición del mercado algodonero causado por la producción del Socorro, lo que incentivó, a su vez, la ganadería extensiva en Pore, Chire y Cravo que eran más aptas para estas labores que la región en donde estaba asentada Santiago de las Atalayas. ${ }^{57}$

El gobernador no se refirió a la situación de la población, no mencionó su calidad y cantidad para el sostenimiento de la ciudad y la administración de justicia. En febrero de 1799, Otero elaboró un mapa en donde se muestra la jurisdicción de la ciudad de Santiago, la ubicación del sitio de Barro Blanco, a donde se pretendió trasladar la ciudad, y la distribución de la población que estaba congregada hacia el norte por lo que la parte sur se hallaba "quasi despoblada" (Figura 2).

Figura 2. Mapa elaborado por el gobernador Feliciano Otero, febrero de 1799. Muestra el sitio de la ciudad de Santiago y el de Barro Blanco

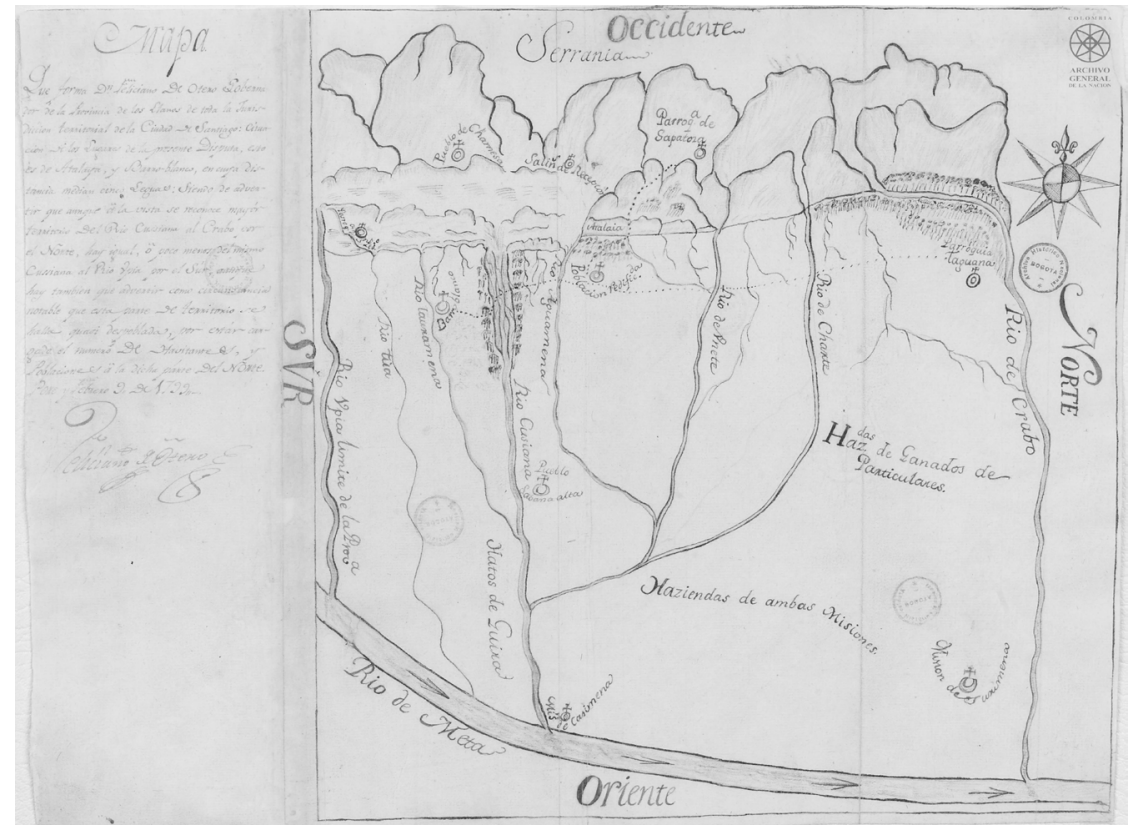

Fuente: “Zona comprendida entre el río Meta y las montañas”, Santiago de las Atalayas, 1799. AGN, Bogotá, Mapas y planos SMP 4, ref. 219A. Nótese la reedificación de Santiago de las Atalayas en las riberas del río Aguamena y la ubicación de Barro Blanco, sitio al que fue trasladada la ciudad en el siglo XVIII. 
En el informe, el gobernador insistió en que de no ser por el temor que sentían los vecinos de las Atalayas a perder el trabajo en la reedificación de la ciudad esta tendría una población más regular y útil en su sitio original, lugar en donde recibió la confirmación de su título, "no pudiéndose negar a los primeros fundadores el espíritu glorioso que los animaba para dejar a la posteridad ventajosas utilidades y mediante ellas inmediato servicio al Estado y Real Haber". ${ }^{58}$ Musset argumentó que la ciudad española estaba fundamentada en unos principios ideológicos y que era la unión de los tres poderes (el rey, la Iglesia y el ayuntamiento) la que daba existencia a la ciudad como entidad política. ${ }^{59}$ El traslado de los centros urbanos en términos materiales no debía ocultar la "existencia espiritual" que se originaba en la fundación de los mismos.

Con estas razones, Feliciano Otero manifestó la necesidad e importancia de reedificar la ciudad en su antiguo sitio, pues se beneficiaría la religión, el Estado y la Corona en vista de que la existencia de las ciudades promueve la vida en policía, pues

Lo escondido del paraje de Barro Blanco ha contribuido mucho para que los vicios y malas costumbres se propaguen en aquellos habitadores (a excepción de muy pocos) en términos que cuando no sean desconocidas entre ellos las máximas del catolicismo no se observan ni veneran con la fe y celo debido [...] Porque esta misma relajación de costumbres les atrae sin duda la indigencia, miseria y consiguientemente la muerte, haciéndose unos vasallos inútiles por su inacción y desorden [...] porque obligándolos a vivir bajo el yugo o gobierno político de la ciudad de Atalaya recordarán del letargo en que han vivido, conocerán las ventajas que ofrece la sociedad y reuniéndose con los muchos vecinos que se agregarán a la restablecida ciudad formarán un cuerpo considerable de habitantes que con su industria, interés o negociaciones aumenten al rey sus reales rentas. ${ }^{60}$

Son evidentes las contradicciones entre los pareceres de los gobernadores y en el cambio de opinión del mismo Feliciano Otero, lo que sugiere la participación de diversos intereses en el traslado de la ciudad. No es factible determinar con certeza la validez de cada uno de los testimonios, mas es posible notar las divisiones internas que sufrió la comunidad política y la sociedad que habitaba en Santiago de las Atalayas por la toma de una decisión que afectaría el futuro de la población, ya sea por sus beneficios o perjuicios. La situación presentada a raíz de este proceso evidencia las luchas que se libraron en los cabildos cuando debían decidir en torno a la mudanza de un centro urbano o a su abandono, algo que se puede extender a todo el Nuevo Reino de Granada. Asimismo, muestra las concepciones sobre la ciudad, la forma como la entendían sus habitantes, las variaciones con respecto a su función en el tiempo y las posibilidades de desarrollo y sostenimiento que se llevaban a cabo en ellas.

58. AGN, Bogotá, Colonia, Poblaciones Boyacá, t. 1 bis, doc. 11, f. 224v.

59. Musset, Ciudades nómadas 314.

60. AGN, Bogotá, Colonia, Poblaciones Boyacá, t. 1 bis, doc. 11, ff. 225v-226r. 
El 13 de noviembre de 1799, el fiscal de la Audiencia determinó que la ciudad debía permanecer en el antiguo sitio y los oficiales de cabildo y justicia debían establecerse en la ciudad, con todo ello se dio por terminado un pleito de 21 años. El fiscal advirtió a los vecinos de Barro Blanco que debían acreditar el derecho a ocupar ese sitio y promover la erección de parroquia, de lo contrario se les obligaría a restituirse a la Atalaya o a otra población para vivir en sociedad civil y cristiana. ${ }^{61}$ La erección de parroquia en Barro Blanco se adelantó en el año de 1801. Las dos poblaciones continuaron en deterioro hasta su extinción hacia los años treinta del siglo XIX. ${ }^{62}$

\section{Conclusiones}

Los argumentos ofrecidos en el proceso de traslado permiten comprender el ideal de ciudad, las divisiones internas de una comunidad, la relación con el entorno geográfico y su incorporación a unos referentes culturales en torno a la definición de sus condiciones de sanidad y prosperidad, así como el papel desempeñado por las autoridades para garantizar la perdurabilidad de los centros urbanos.

Determinar cuáles eran los aspectos que permitían la perpetuidad de la ciudad en el período colonial es bastante complejo, puesto que la exposición de causas para justificar un movimiento del centro urbano estaba ligada a los intereses de ciertos grupos. En esencia, cuando se efectuaba un traslado se apoyaba en la idea de buscar un mejor lugar de asentamiento, es por eso que se exponía la dialéctica de lo sano y malsano para señalar el bienestar que se esperaba con el cambio y la precariedad del lugar original. Sin embargo, cuando se comparan estos argumentos con otros informes, incluso de períodos precedentes, se identifica que las condiciones naturales no eran, en sentido estricto, como se describían cuando se buscaba dar legitimidad a una decisión de traslado.

En el caso de Santiago de las Atalayas se puede ver una lucha de intereses económicos que se vieron afectados a partir del traslado de la ciudad, ya que quienes pretendieron consolidar un nuevo asentamiento lo hicieron para tener mayor cercanía a sus haciendas, algo que se veía desde el siglo XVII por el marcado despoblamiento ligado a que el sostenimiento de sus habitantes estaba por fuera del centro urbano. Asimismo, quienes se quedaron en el sitio original de la ciudad lo hicieron por la imposibilidad de construir sus viviendas en otro lugar. Bajo un escenario que pone en evidencia las circunstancias ambientales y económicas que afectaban a los habitantes de la ciudad también es posible identificar las estrategias para fortalecer las pretensiones de ambos grupos, y resulta interesante que fue bajo esas condiciones en donde emergió todo un debate sobre la ciudad, su significado y la importancia de su permanencia.

61. AGN, Bogotá, Colonia, Poblaciones Boyacá, t. 1 bis, doc. 11, ff. 276r-276v.

62. Castro 334. 
Ad portas de un fracaso en el poblamiento y en la construcción de la república la comunidad que dio vida a la ciudad y que la sostuvo en términos simbólicos, culturales, políticos y económicos luchó por su preservación, lo que demuestra que es el interés de la comunidad política y moral, lo que en esencia permitía la conservación y perpetuidad de la misma. Pese a las condiciones adversas del entorno geográfico y del marcado despoblamiento, la ciudad de Santiago de las Atalayas logró mantenerse por más de dos siglos y, en el momento crucial de traslado, expuso que era la voluntad general y el bienestar común lo que debía prevalecer y no el interés particular de cierto grupo que a pesar de ser el cabildo iba en contra de las disposiciones y la autoridad real; algo que también refleja las tensiones entre los diferentes niveles del poder y cómo la Corona procuró materializar sus disposiciones a escala local.

El traslado de Santiago de las Atalayas revela las tensiones internas que suscitaba una decisión de este orden, algo que se puede pensar para los demás procesos de mudanzas que se dieron en el Nuevo Reino de Granada y de los cuales no hay registros tan completos y ricos en detalles. Esas tensiones permiten pensar en los cambios que se manifestaron en las comunidades políticas que sostenían los centros urbanos; es decir, en un principio esa comunidad eran los vecinos encomenderos, descendientes de conquistadores, los oficiales de cabildo que debían velar por el mantenimiento de ciudades y villas. Es bastante sugerente, en este caso, que la determinación de la Audiencia desautorizara el traslado y dejara de lado el hecho de que los gobernadores, cabildos y vecinos principales apoyaron dicha mudanza a partir de demostrar que eran ellos quienes podían sostener y dar prosperidad a la ciudad, lo cual deja ver un interés por el bienestar común.

La solidez y coherencia de los argumentos de quienes querían trasladar la ciudad no fueron suficientes, puesto que este era el lugar en donde la comunidad lograba desarrollar una vida perfecta, en policía, bajo unos referentes culturales de unidad, algo que se rompió con el proceso de traslado y la ineptitud administrativa de gobernadores y oficiales de la Audiencia que tardaron más de veinte años en tomar una decisión definitiva. Por lo cual en 1798 el cabildo de la ciudad mencionó la miseria y ruina en la que permanecía como consecuencia de esos años de traslado y por el cual debían emprender la reedificación en el sitio original de la Atalaya. ${ }^{63}$

Uno de los aspectos más sobresalientes de todo este proceso de traslación y del esfuerzo llevado a cabo por cada grupo para justificar las medidas que debían favorecer su bienestar es la demostración de que el ideal de ciudad no era un discurso impuesto desde arriba, ni mucho menos un imaginario que solo concernía a teóricos o autoridades encargadas de regular el poblamiento, sino que era un pensamiento que albergaba la población, que se usó de manera retórica y diferenciada para apoyar cada decisión y que se procuró materializar en los proyectos

63. "Certificado reedificación Santiago de las Atalayas", Santiago de las Atalayas, 1798-1819. AGN, Bogotá, Colonia, Miscelánea, t. 126, doc. 36, ff. 770r-772v. 
urbanísticos. Asimismo, este caso específico muestra los cambios ocurridos en el trascurso de tres siglos en los cuales la función y utilidad de los centros urbanos se transformó de ser un punto de defensa y avanzada en la conquista a ser un lugar de prosperidad económica y de fomento de una vida civil y en policía. Al respecto, la adecuación del discurso de la ciudad a las nuevas condiciones fue excepcional, pues mantenían los pilares básicos que la definían en términos de la civitas y la urbs, pero debía responder a las necesidades actuales de sus habitantes sin perder el horizonte que la ubicaba como un eslabón en todo el entramado imperial.

\section{Fuentes}

\section{Manuscritas}

Archivo General de Indias, Sevilla (AGI)

Fondo Estado

Archivo Histórico Nacional, Sevilla (AHN)

Fondo Colección Documentos de Indias

Archivo General de Simancas, Simancas (AGS)

Fondo Secretaría de Estado y del Despacho de Guerra

Archivo General de la Nación, Bogotá (AGN)

Fondo Colonia

\section{Impresas}

Botero, Giovanni. Delle cause della grandezza delle citta. Roma: Giovanni Martinelli, 1588.

Covarrubias, Sebastián de. Tesoro de la lengua castellana o española. Madrid: Luis Sánchez, 1611.

De Oviedo, Basilio Vicente. Cualidades y riquezas del Nuevo Reino de Granada. Bogotá: Imprenta Nacional, 1930.

Transcripción de las ordenanzas de descubrimiento, nueva población y pacificación de las Indias dadas por Felipe II, el 13 de julio de 1573, en el Bosque de Segovia, según el original que se conserva en el Archivo General de Indias de Sevilla. Madrid: Ministerio de Vivienda, 1973.

\section{Bibliografía}

Acosta Franco,Yirla Marisol. Mudanzas y desasosiegos de los cristianos: ciudades móviles del Occidente del Nuevo Reino de Granada, 1509-1611. Medellín: Instituto para el Desarrollo de Antioquia, 2015.

. "Traslados y abandonos de ciudades y villas en el Nuevo Reino de Granada y Popayán, siglos XVI y XVII”. Tesis de Maestría en Historia, Universidad de Antioquia, 2017. 
Álvarez, Salvador. "Poblamientos y abandonos en la frontera septentrional novohispana. Los pueblos de hacienda del antiguo valle de San Bartolomé". Trace 43 (2003): 38-55.

Aristóteles. Política. Madrid: Centro de Estudios Políticos y Constitucionales, 1997. Calvo, Thomas. "Una adolescencia americana. Las ciudades del Nuevo Mundo hispánico hasta 1600". Historias 71 (2008): 101-132.

Castro Roldán, Andrés. "Santiago de las Atalayas: una ciudad de la frontera en el Nuevo Reino de Granada (XVI-XVIII)". Fronteras de la Historia 12 (2007): 301-339.

García Bernal, Manuela Cristina. "Las élites capitulares indianas y su poder en el siglo XVII". Anuario de Estudios Americanos 57.1 (2000): 89-110. ."Sobre cabildos y élites en Yucatán". Mesoamérica 21.39 (2000): 418-424.

Lucena Giraldo, Manuel."La fundación de América a través de su historia urbana". Memorias de ciudad. Urbanismo y vida urbana en Iberoamérica colonial. Bogotá: Alcaldía Mayor de Bogotá, 2008.

Musset, Alain. "Abandonos y traslados de ciudades en Hispanoamérica. Historia en el olvido, memoria de los lugares". Trace 43 (2003): 25-37.

. Ciudades nómadas del Nuevo Mundo. México: Fondo de Cultura Económica, 2011.

Rodríguez, Pablo. Cabildo y vida urbana en el Medellín colonial, 1675-1730. Medellín: Universidad de Antioquia, 1992.

Sennett, Richard. Carne y piedra. El cuerpo y la ciudad en la civilización occidental. Madrid: Alianza, 2007. 